\title{
PRODUÇÃO AGROPECUÁRIA, AGREGAÇÃO DE VALOR E COMERCIALIZAÇÃO PELA AGRICULTURA FAMILIAR NO ESTADO DO MATO GROSSO DO SUL
}

\section{AGRICULTURAL PRODUCTION, VALUE ADDING AND MARKETING BY FAMILY FARMING IN THE STATE OF MATO GROSSO DO SUL}

\author{
Jaqueline Silva Nascimento \\ Embrapa Agropecuária Oeste - Dourados - MS - Brasil
}

Gleicy Jardi Bezerra

Universidade Federal do Rio Grande do Sul - Porto Alegre - RS

\section{Madalena Maria Schlindwein}

Universidade Federal da Grande Dourados - Dourados - MS - Brasil

\section{Milton Parron Padovan}

Embrapa Agropecuária Oeste e Universidade Federal da Grande Dourados -

Dourados - MS - Brasil

\begin{abstract}
Resumo: A agricultura familiar possui relevada importância socioeconômica em Mato Grosso do Sul, sendo responsável por uma parcela expressiva na geração de empregos e renda no estado. Destaca-se no quesito desenvolvimento local, minimizando o êxodo rural e promovendo a segurança alimentar e nutricional. Mesmo assim, no entanto, diferentes organizações representativas dos agricultores relatam que esse segmento enfrenta sérios problemas em diferentes elos das cadeias produtivas. É nesse contexto que se desenvolveu este estudo e com o intuito de identificar as principais atividades produtivas desenvolvidas para a geração de renda, alguns aspectos sobre agregação de valor à produção e canais de comercialização, bem como procurando visualizar soluções para melhorar a venda dos produtos produzidos pela agricultura familiar no estado. O estudo foi realizado em julho de 2014 , envolvendo 30 agricultores oriundos de diferentes regiões de Mato Grosso do Sul. Os dados foram obtidos a partir de entrevistas realizadas de forma aleatória durante eventos da área. Para as entrevistas, utilizou-se um roteiro semiestruturado, composto por questões abertas e fechadas. As informações coletadas foram organizadas e processadas eletronicamente. Para isso, utilizou-se o software Statistical Package for the Social Sciences - SPSS (versão 21). Os resultados mostram que a maioria dos agricultores declarou que agregam valor à produção, porém, que esse processo é feito,
\end{abstract}


predominantemente, de forma artesanal e principalmente para o autoconsumo. A venda direta é a modalidade de comercialização mais comum para esses agricultores, em ambiente em que a venda aos atravessadores ainda é elevada. O escoamento da produção é o principal gargalo no processo de comercialização. Assim, conclui-se que há muitas dificuldades para o desenvolvimento sustentável da agricultura familiar em Mato Grosso do Sul, com necessidade urgente da adoção de posturas proativas dos governos para apoiá-la, o que deve ser promovido em todos os elos das cadeias produtivas.

Palavras-chave: Cadeias produtivas. Agregação de valor à produção. Desenvolvimento local e regional.

Abstract: Family farming has a huge socioeconomic importance in Mato Grosso do Sul, accounting for a significant portion in generating jobs and income in the state. It stands out in the category local development, minimizing rural exodus and promoting food and nutrition security. Even so, different organizations representing farmers report that this sector faces serious problems in different productive chains links. It is in this context that this study was performed in order to identify the main productive activities aiming income generation, some aspects of value adding to production and marketing channels, as well as targeting to discuss solutions to improve the sale of family farming products in the state. The study was conducted in July 2014, involving thirty farmers from different regions of Mato Grosso do Sul. The data were obtained from random interviews during area events. A semi-structured questionnaire with open and closed questions composed the interviews. The material was organized and processed electronically, using the software Statistical Package for Social Sciences SPSS (version 21). The results show that most farmers declared that add value to the production, but that this process occurs, especially, for self-consumption and has handmade characteristics. Direct selling is the most common marketing method for these farmers in a location where the sale to intermediaries is still high. Production flow is the main bottleneck in the marketing process. Thus, it is concluded that there are many difficulties for the sustainable development of family farming in Mato Grosso do Sul, with urgent need to adopt proactive stances from governments to support it, which should be promoted in all production chains links.

Keywords: Production chains. Value adding to the production. Local and regional development.

\section{Introdução}

O setor agropecuário no Estado de Mato Grosso do Sul movimentou 13,9 bilhões de reais no ano de 2014; desse total, 61,5\% referem-se ao setor agrícola, representando uma participação de 18,3\% do Produto Interno Bruto - PIB total da economia do estado (FAMASUL, 2015). Segundo dados do Ministério da Agricultura, Pecuária e Abastecimento - MAPA (2015), o segmento do agronegócio tem crescido 
expressivamente no comércio internacional desde 1990, sendo que o Brasil é responsável por $25 \%$ dos produtos que circulam no mercado internacional.

Com base no último censo agropecuário, do ano de 2006, a agricultura familiar brasileira compreendia 4.367.902 estabelecimentos, o que representa $84,4 \%$ dos estabelecimentos agropecuários, detendo $74,4 \%$ da ocupação de pessoal no meio rural, com 12,3 milhões de pessoas. É detentora de $10 \%$ do PIB do país, com produção correspondente a 54 bilhões de reais. Isso significa $38 \%$ do valor bruto gerado pela agricultura (IBGE, 2006; MDA, 2015).

No Estado de Mato Grosso do Sul, a agricultura familiar corresponde a $14 \%$ do Valor Bruto da Produção Agropecuária - VBP, instalada em 41.104 estabelecimentos, correspondentes a $65 \%$ das propriedades rurais. Assim instalada, a agricultura familiar é responsável por $46 \%$ do pessoal ocupado no meio rural, o que corresponde a 97.431 pessoas (GUILHOTO et al., 2007).

No contexto agropecuário, insere-se a agricultura patronal e a agricultura familiar, sendo ambas segmentos produtivos de grande relevância para o país. Azevedo e Pessôa (2011) relatam algumas características da agricultura não familiar, ou seja, da agricultura patronal, com definições destacadas pela FAO/INCRA (1994), sendo: organização centralizada, ênfase na especialização e práticas agrícolas patronáveis, separação dos fatores de gestão e de trabalho, predominância do trabalho assalariado, tecnologias direcionadas que buscam a redução da mão de obra e foco em insumos comprados.

O termo "agricultura familiar" teve avanços significativos nas últimas décadas com relação à sua definição e compreensão de suas características (SCHNEIDER; CASSOL, 2014). Conforme consta na Lei Federal $n^{\circ} 11.326$, de 24 de julho de 2006, no artigo $3^{\circ}$ (BRASIL, 2014), são destacadas como características primordiais: não possuir área maior do que 4 (quatro) módulos fiscais; a mão de obra utilizada nas atividades econômicas ser predominantemente familiar e o maior percentual da renda ser obtida das atividades econômicas do estabelecimento. Assim, Hanashiro et al. (2011) destacam que a produção da agricultura familiar abastece predominantemente $\mathrm{o}$ mercado interno, enquanto o principal objetivo econômico da agricultura patronal é o mercado externo. 
Nesse contexto, com o entendimento de que a agricultura familiar brasileira é uma categoria social e produtiva, a partir dos anos de 1990, algumas políticas públicas foram formuladas com o intuito de garantir a reprodução, enquanto segmento produtivo, principalmente visando à produção de alimentos básicos, além da fixação do homem no meio rural, primando pela qualidade de vida (SOUZA-ESQUERDO; BERGAMASCO, 2014).

Uma das políticas públicas criadas para apoiar os agricultores familiares foi o Programa Nacional de Fortalecimento da Agricultura Familiar - PRONAF, criado em 1996. Essa política pública tem como objetivo introduzir o uso de tecnologias modernas no setor agrícola e pecuário, sendo a principal fonte de recursos financeiros, seja para custeio de safra ou atividade agroindustrial, contribuindo para a melhoria dos aspectos econômicos e sociais das famílias (MDA, 2015).

A implementação do PRONAF teve contribuição significativa para o aumento nas atividades produtivas geradoras de renda e no desenvolvimento rural (MATTEI, 2014). Assim, é importante ressaltar que a agricultura familiar está ganhando destaque pela sua participação na disponibilização de alimentos, oferecidos aos diferentes mercados, tanto na forma in natura quanto industrializados de alguma forma (AGNE; WAQUIL, 2011).

Maluf e Menezes (2000), Guanziroli et al. (2001), Leite et al. (2004), Norder (2004) e Furlaneto, Oliveira e Andrade (2012) ressaltam que instituições governamentais apostam a agricultura familiar como essencial para promover a segurança alimentar e nutricional no Brasil.

Entretanto, a agricultura familiar sempre foi vista como uma agricultura apenas para subsistência. Ainda há discussões sobre a importância do segmento, porém diversos autores destacam, a partir de estudos realizados, vantagens na eficiência produtiva e na otimização do uso de recursos locais utilizados em unidades de produção da agricultura familiar quando comparadas a propriedades rurais de base patronal. Há diversos estudos que evidenciam que a agricultura familiar possui boa capacidade de gerar empregos, contribuindo estrategicamente para ao desenvolvimento local e regional (COSTA; RIMKUS; REYDON, 2008).

Dentre as formas de gerar renda na agricultura familiar, destacase a pluriatividade, em que a renda é obtida tanto da atividade agrícola 
quanto de outras formas de atividades, sendo essas receitas vindas de dentro ou de fora das propriedades rurais (FULLER, 1990). Para os agricultores familiares, agregar valor à sua produção facilita a inserção desses produtos no mercado, destacando que as agroindústrias familiares processam e/ou transformam parte da produção agrícola e/ou pecuária, visando, sobretudo, à produção de valor de troca que se realiza na comercialização (MIOR et al., 2014).

Pensando no desenvolvimento das propriedades rurais, as políticas públicas de custeio agrícola são essenciais para favorecer o desenvolvimento econômico, social e fortalecer os agricultores familiares (SANGALLI; SCHLINDWEIN, 2013). Mesmo assim, no entanto, apesar de alguns avanços obtidos na última década no Brasil, os agricultores familiares ainda enfrentaram sérios problemas de falta de mercado para seus produtos, especialmente os alimentos, e uma das maneiras de inserir essa produção no mercado é investir na demanda institucional (COSTA; RIMKUS; REYDON, 2008; PADUA-GOMES; PADOVAN, 2014). Dentre as políticas públicas de apoio à comercialização da produção da agricultura familiar, destacam-se o Programa de Aquisição de Alimentos - PAA e o Programa Nacional de Alimentação Escolar - PNAE.

Tendo em vista que as áreas que estão sob o domínio da agricultura familiar são consideradas pequenas, os agricultores precisam adotar algumas estratégias de produção especiais para viabilizar retorno financeiro. Vale ressaltar a importância dos estabelecimentos da agricultura familiar no segmento do agronegócio, como responsáveis por $70 \%$ da produção de alimentos no país. Razão pela qual são importantes aliados no desenvolvimento local sustentável, por meio da geração de renda e emprego, na redução do êxodo rural e na promoção da segurança alimentar e nutricional (MONEGO et al., 2013).

Diante do contexto, desenvolveu-se este estudo com os objetivos de identificar as principais atividades produtivas desenvolvidas para a geração de renda pelos agricultores familiares, bem como aspectos relacionados à agregação de valor à produção e canais de comercialização, e as possíveis soluções para melhorar a venda dos produtos produzidos pela agricultura familiar no estado. 
Para atingir os objetivos propostos neste estudo, foram realizadas entrevistas no mês de julho de 2014 , durante a $10^{\text {a }}$ Feira de Sementes Nativas e Crioulas e de Produtos Agroecológicos e o $3^{\circ}$ Seminário sobre o Uso e Conservação do Cerrado do Sul de Mato Grosso do Sul, realizados em Juti/MS.

Com base em um roteiro semiestruturado, composto por questões abertas e fechadas, foram entrevistados 30 agricultores oriundos dos Municípios de Corumbá, São Gabriel do Oeste, Ponta Porã, Itaquiraí, Nova Andradina, Mundo Novo, Bodoquena, Ladário, Terenos, Novo Horizonte do Sul, Amambai, Dourados, Juti, Bandeirantes e Nioaque, todos localizados no Estado de Mato Grosso do Sul.

Durante os eventos supramencionados, os agricultores foram abordados aleatoriamente e convidados para participarem da pesquisa. Foram explicados, a cada um, os objetivos da pesquisa, bem como a sistemática que seria adotada.

As informações coletadas foram organizadas e processadas eletronicamente utilizando-se o software SPSS (versão 21), e que são apresentadas em tabelas e gráficos, analisadas, interpretadas e discutidas.

\section{Resultados e discussões}

Esta seção refere-se à análise dos dados encontrados a partir das entrevistas realizadas, dividindo-se em: (i) atividades desenvolvidas pelos agricultores familiares e agregação de valor à produção e (ii) comercialização da produção: possibilidades e melhorias. 
2.1 Atividades desenvolvidas pelos agricultores familiares e agregação de valor à produção

Fazendo uma análise dos dados encontrados na pesquisa de campo, dados obtidos por meio de entrevistas, verifica-se que o tamanho das propriedades varia entre 01 e 28 hectares, conforme apresentado na Tabela 1.

Tabela 1. Agricultores familiares de Mato Grosso do Sul participantes da pesquisa e os respectivos tamanhos das propriedades rurais

\begin{tabular}{c|c|c}
\hline $\begin{array}{c}\text { Tamanho da propriedade } \\
\text { (ha) }\end{array}$ & $\begin{array}{c}\text { Agricultores } \\
\text { entrevistados }\end{array}$ & $\begin{array}{c}\text { Percentual de agricultores } \\
(\%)\end{array}$ \\
\hline 1 & 1 & 3,33 \\
4 & 2 & 6,67 \\
5 & 3 & 10,00 \\
6 & 1 & 3,33 \\
7 & 3 & 10,00 \\
8 & 2 & 6,67 \\
10 & 1 & 3,33 \\
12 & 1 & 3,33 \\
13 & 1 & 3,33 \\
14 & 2 & 6,67 \\
16 & 1 & 3,33 \\
17 & 4 & 13,34 \\
18 & 2 & 6,67 \\
20 & 1 & 3,33 \\
21 & 2 & 6,67 \\
22 & 2 & 6,67 \\
28 & 1 & 3,33 \\
\hline
\end{tabular}

Fonte: Dados da pesquisa, 2014.

Nota-se que todas as unidades de produção possuem menos de 30 hectares, sendo que $20 \%$ dos respondentes possuem até 5 hectares; $43,33 \%$ possuem até 10 hectares e $83,33 \%$ possuem até 20 hectares. Um dado bastante interessante é que apenas $16,67 \%$ dos respondentes possuem mais que 20 hectares. Assim, são pequenas áreas que requerem ações estratégicas para viabilizar produções suficientes que garantam renda satisfatória às famílias.

De acordo com Gazolla et al. (2013), a diferença no tamanho das propriedades da agricultura familiar pode influenciar na produção agropecuária, nas características socioeconômicas e ambientais, na 
gestão das áreas e mão de obra, impactando na geração de renda. Nesse contexto, ressalta-se a importância da diversidade de cultivos nas propriedades rurais, o que contribui para o equilíbrio ecológico nos agroecossistemas, além de propiciar geração de renda mais segura aos produtores (MARTINEZ; PEIL, 2013).

Na Tabela 2, são apresentadas as principais atividades geradoras de renda nas unidades de produção familiar analisadas em Mato Grosso do Sul. 
Tabela 2. Principais atividades geradoras de renda desenvolvidas em propriedades da agricultura familiar em Mato Grosso do Sul

\begin{tabular}{c|c|c}
\hline Principal fonte de renda da propriedade* & $\begin{array}{c}\text { Número de } \\
\text { propriedades em } \\
\text { que a atividade é } \\
\text { realizada }\end{array}$ & Percentual** \\
\hline Leite & 17 & 56,67 \\
Mandioca & 13 & 43,33 \\
Frutas (banana, maracujá, abacaxi, goiaba, melão, & 12 & 40,00 \\
limão) & 10 & 33,33 \\
Hortaliças & 8 & 26,67 \\
Doces (doces de leite e abóbora, geleias) & 6 & 20,00 \\
Milho & 5 & 16,67 \\
Abóbora & 5 & 16,67 \\
Artesanato & 5 & 16,67 \\
Frango & 5 & 16,67 \\
Quiabo & 4 & 13,33 \\
Ovos & 3 & 10,00 \\
Feijão & 2 & 6,67 \\
Urucum & 2 & 6,67 \\
Algodão & 2 & 6,67 \\
Soja & 1 & 3,33 \\
Tempero caseiro & 1 & 3,33 \\
Maxixe & 1 & 3,33 \\
Batata & 1 & 3,33 \\
Cana-de-açúcar & & 100,00 \\
\hline TOTAL & & \\
\hline paras & & \\
\hline
\end{tabular}

Fonte: Dados da pesquisa, 2014.

*O entrevistado pode assinalar mais de uma alternativa.

** O percentual foi calculado com base nos 30 (trinta) entrevistados.

Constatou-se que $56,67 \%$ dos agricultores entrevistados desenvolvem a atividade de produção leiteira como a principal fonte renda nas unidades de produção. Para $43,33 \%$ dos produtores, a mandioca é a atividade predominante. Em $40 \%$ das propriedades, são as frutas que se constituem na maior fonte de renda, seguida por hortaliças (33,33\% dos produtores), como pode ser observado na Tabela 2.

Outro fato que merece destaque é que $26,67 \%$ dos agricultores têm como a principal fonte de renda a fabricação de doces confeccionados com matérias-primas produzidas nas respectivas unidades de produção, o que mostra a existência de possibilidades importantes de agregação de valor e obtenção de melhores rendas nas propriedades rurais. Destacam-se ainda como importantes atividades 
geradoras de renda, a produção de milho, abóbora, artesanatos, frango caipira, quiabo, ovos e feijão. O urucum, soja e algodão são as principais atividades geradoras de renda, porém para um número bem mais restrito de agricultores.

A importância de agregação de valor para o desenvolvimento das propriedades rurais é discutida por vários autores, como por exemplo, Buainaim e Romeiro (2000), os quais relatam que a agricultura familiar possui mecanismos de produção e se fortalece ao diversificar os cultivos e as criações, porém destaca-se ainda mais ao optar pela transformação desses produtos, tanto para consumo próprio, como para comercializálos.

Vilckas et al. (2011) e Nascimento et al. (2014) também reforçam que a agregação de valor à sua produção, para os agricultores familiares, pode ser uma importante estratégia com intuito de aumentar a rentabilidade nas unidades de produção, contribuindo para a geração de renda, além de comercializá-los com outro valor agregado, que é o valor social, por ser oriundo da agricultura familiar, podendo acessar mercados diferenciados.

Com base nos dados coletados, relatou-se que $70 \%$ dos agricultores agregam valor aos alimentos produzidos nas propriedades e apenas 30\% não agregam valor à sua produção (Figura 1). Apesar do elevado número de agricultores familiares que afirmam agregarem valor à produção, esse processo é feito, predominantemente, de forma artesanal, e com apenas parte da produção, principalmente para consumo próprio.

Figura 1. Agregação de valor à produção rural por parte de agricultores familiares de Mato Grosso do Sul

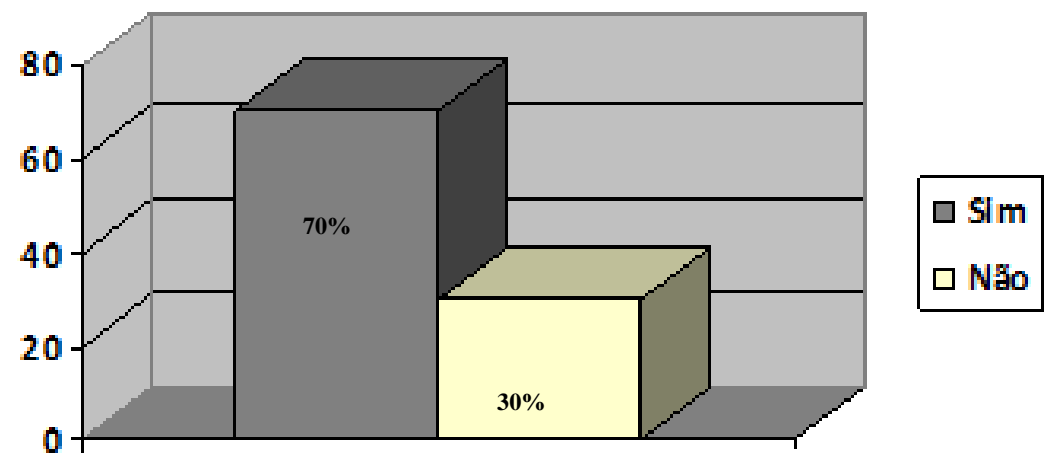

Fonte: Dados da pesquisa, 2014. 
Analisando os resultados da Figura 1, é perceptível o expressivo percentual de agricultores entrevistados que agregam valor à sua produção. Assim, essa afirmação é corroborada ao serem analisados os resultados apresentados na Tabela 2, onde uma amostra de $26,67 \%$ dos entrevistados fazem doce com produtos oriundos de sua produção. Mesmo assim, no entanto, muitas vezes é difícil para esses produtores processarem seus produtos de forma isolada, o que reforça a necessidade de se unirem em associações e cooperativas, o que certamente possibilita a conquista de muitos avanços nesse sentido.

Para a agricultura familiar, o beneficiamento ou processamento da matéria-prima, agregando maior valor à produção é de fundamental importância. Representa uma alternativa sustentável e descentralizada para a produção em pequenas escalas, com possibilidades de fornecimento de produtos diferenciados e com maior valor agregado (LOURENZANI et al., 2004; GRUNERT, 2005; WANDERLEY, 2013).

A agregação de valor à produção oriunda da agricultura familiar pertence à dinâmica da cadeia produtiva mediante a agroindustrialização em pequena escala, como o processamento de frutas, transformando-se em geleias e doces, verduras e legumes sendo produzidos como conservas, dentre outros (RADWANSKI et al., 2014).

\subsection{Comercialização da produção: possibilidades e melhorias}

No que se refere à comercialização, a partir dos dados coletados (Tabela 3), observa-se que os agricultores participantes da pesquisa possuem dois tipos de canais para comercializar sua produção: venda direta e atravessador.

Tabela 3. Canais de comercialização dos produtos da agricultura familiar em Mato Grosso do Sul

\begin{tabular}{c|c|c}
\hline Variáveis Selecionadas & Produtores $^{*}$ & Percentual $^{* *}$ \\
\hline Atravessador & 14 & 46,67 \\
Venda direta & 30 & 100,00 \\
\hline
\end{tabular}

Fonte: Dados da pesquisa, 2014.

*O entrevistado pode assinalar mais de uma alternativa.

** O percentual foi calculado com base nos 30 (trinta) entrevistados. 
Constatou-se que todos os produtores utilizam a venda direta como um dos principais canais de comercialização e, no entanto, 46,67\% deles também comercializam por intermédio de atravessadores. Ressalta-se que, com a venda direta ao consumidor, tem-se uma diminuição nos custos de transação, possibilitando ao produtor a obtenção de maior lucratividade.

Segundo Wilkinson (2008), é possível identificar alguns canais de comercialização da agricultura familiar, tais como: acesso direto, sobretudo no caso do mercado local (informal); intermediação via atravessador; integração com agroindústrias e compras por parte do poder público.

É importante considerar algumas dificuldades de comercialização da agricultura familiar citadas por Santos e Mitja (2012), como a distância dos centros de comercialização, infraestrutura de transporte e estradas, acesso ao mercado, pontos de venda, dentre outros.

Diante desse contexto, os agricultores entrevistados elencam algumas soluções que poderiam contribuir para a comercialização de seus produtos. Dentre as mais citadas, destaca-se a melhoria da infraestrutura no transporte, uma vez que se constatou que $26,67 \%$ dos entrevistados consideram a infraestrutura de transporte como a principal solução para melhorar a comercialização. Isso se deve às dificuldades no deslocamento dos produtos das unidades de produção até os locais de comercialização, devido à distância das propriedades até os locais de venda e inadequação das estradas, e também por falta de transporte planejado para esse fim (Tabela 4).

Assim, muitos produtos locais deixam de ser comercializados, tendo como consequência a diminuição da renda dos agricultores e a maior dependência da vinda de produtos de outras regiões do estado e até de outras regiões do país para atender às demandas dos consumidores dos núcleos urbanos dos municípios. 
Tabela 4. Soluções apontadas pelos agricultores entrevistados para melhorar a comercialização dos produtos produzidos pela agricultura familiar em Mato Grosso do Sul

\begin{tabular}{c|c|c}
\hline Variáveis selecionadas & $\begin{array}{c}\text { Número de } \\
\text { agricultores }^{*}\end{array}$ & $\begin{array}{c}\text { Porcentage } \\
\mathbf{m}^{* *}\end{array}$ \\
\hline Melhoria da infraestrutura no transporte & 8 & 26,67 \\
Apoio na construção de agroindústrias locais & 6 & 20,00 \\
União dos agricultores & 5 & 16,67 \\
Ampliação de canais de comercialização & 5 & 16,67 \\
Apoio às feiras coletivas nos municípios & 3 & 10,00 \\
Melhoria de preços na comercialização & 3 & 10,00 \\
Apoio do governo (ATER, outros) & 3 & 10,00 \\
Divulgação dos produtos (propaganda) & 2 & 6,67 \\
Aumento dos recursos financeiros disponibilizados & 2 & 6,67 \\
Capacitação dos agricultores & 2 & 6,67 \\
Selo de garantia dos produtos orgânicos & 2 & \\
Melhoria das embalagens e das rotulagens & 1 & 3,33 \\
\hline
\end{tabular}

Fonte: Dados da pesquisa, 2014.

*O entrevistado pode assinalar mais de uma alternativa.

** O percentual foi calculado com base nos 30 (trinta) entrevistados.

Segundo Correia et al. (2013), uma das maiores carências da agricultura familiar refere-se à infraestrutura, carências que compreendem desde estradas de má qualidade a falta de transporte planejado da produção para os locais de comercialização, o que contribui para que os agricultores fiquem à mercê de intermediários para comprarem as suas produções.

Essa questão das estradas e do transporte especializado para a produção é uma grande carência. Outra carência, conforme apresentado na Tabela 4, é a indicada por $20 \%$ dos agricultores, que entendem que a construção de agroindústrias locais é de suma importância. Esse processo pode favorecer a comercialização da produção utilizando-se dos canais locais de comercialização nos seus respectivos municípios de origem, o que também contribui estrategicamente para o desenvolvimento local e regional (DINIZ; FIGUEIREDO, 2011; SANTOS; MITJA, 2012). Santos e Mitja (2012), em um estudo desenvolvido no Sudeste do Pará, constataram que a dificuldade de comercialização encontrada pelos agricultores familiares constitui-se num dos maiores desestímulos à produção agrícola regional. Os autores relatam também que há necessidade de promover capacitações para a agroindustrialização da produção destinada à comercialização, 
agregando valor à produção diversificada dos agricultores, contribuindo para a inserção desses produtos processados nos mercados locais, aumentando a renda das famílias.

Outro resultado bastante interessante constatado neste estudo é que $26,67 \%$ dos agricultores consideram a união profissional entre eles como uma necessidade premente e que poderá influenciar sobremaneira na comercialização da produção (Tabela 4). Esse sentimento expresso pelos agricultores é muito importante, pois essa consciência da necessidade pode estimular iniciativas para o fortalecimento da coletividade, como associações e/ou cooperativas, o que poderá influenciar positivamente em vários outros aspectos, como em processos de compras de insumos, por exemplo, ou na adoção de inovações na condução das suas atividades produtivas ou, ainda, na agregação de valor, entre outros processos.

Assim, com relação a uma terceira carência, se uma reorganização profissional se faz necessária nas comunidades produtivas, ela se junta a uma quarta a ser solucionada, que é a ampliação de canais de comercialização e de apoio às feiras coletivas nos municípios, o que foi elencado por $16,67 \%$ e $10 \%$ dos agricultores entrevistados, respectivamente, como de elevada relevância para melhorar a comercialização dos produtos oriundos da agricultura familiar em Mato Grosso do Sul (Tabela 4). O que se informa sobre a atual situação é que, face às poucas alternativas de canais de comercialização existentes nos municípios, principalmente aqueles municípios de menor contingente populacional, aliado à falta de escala de produção de determinados produtos e à sazonalidade da produção, os agricultores encontram severas dificuldades para comercializarem as suas produções.

Pensando em melhorar a competitividade dos produtores familiares, uma alternativa é a organização em cooperativas. Assim, na cooperação tem-se a união das competências individuais em prol de um objetivo comum ao grupo, sendo, dessa forma, possível superar comportamentos individualistas (SILVA et al., 2014).

Estevam et al. (2011), com intuito de auxiliarem no processo de comercialização da produção diversificada da agricultura familiar, apresentam, a partir de experiências implementadas no Estado de Santa Catarina, um modelo alternativo de cooperativismo denominado "cooperativa virtual" ou "cooperativa não-patrimonial", que possui 
diferenças em relação ao modelo tradicional de cooperativa, uma vez que não possui patrimônio. Os autores ressaltam que essa forma de organização é capaz de solucionar as principais dificuldades encontradas no processo de comercialização dos produtos da agricultura familiar, pois garante o aparato jurídico para tal, facilita a comunicação com potenciais clientes, além de implicar baixos custos de manutenção da entidade.

Outras demandas foram elencadas pelos agricultores para fortalecer os processos de comercialização da produção da agricultura familiar em Mato Grosso do Sul, tais como: apoio do governo (assistência técnica e extensão rural - ATER, outros), divulgação dos produtos (propaganda), aumento dos recursos financeiros disponibilizados, capacitação dos agricultores, selo de garantia dos produtos orgânicos e melhoria das embalagens e rotulagem dos produtos (Tabela 4).

Os resultados obtidos neste estudo (Tabela 4) evidenciam que agricultura familiar necessita de posturas proativas dos governos para apoiá-la em todas as etapas das cadeias produtivas. Sem essas políticas fica dificultada a produção e a diversificação de produtos e, se não têm acesso aos mercados, os agricultores familiares não conseguirão renda satisfatória que atenda às suas necessidades básicas e precisarão sair do meio rural em busca de outras opções para garantirem renda e melhor qualidade de vida.

Nesse sentido, Bezerra e Schlindwein (2014) enfatizam que a agricultura familiar possui relevante importância na produção de alimentos, porém necessita-se de um suporte de agentes públicos para ligar alguns elos do setor que isoladamente acabam dificultando a produção e a comercialização, afetando significativamente o desenvolvimento da agricultura familiar.

Fica evidente que a agricultura familiar desempenha um papel fundamental para o desenvolvimento socioeconômico, com intuito de promover um crescimento mais equitativo e equilibrado, com produção de alimentos e geração de empregos. Além disso, uma agricultura familiar forte é responsável pela diminuição do êxodo rural e contribui ativamente para a geração de riqueza, não somente no setor agropecuário, como também para a economia do Estado de Mato Grosso do Sul (BARCELOS; REIS, 2015). 
Nesse contexto, reforça-se a importância da agricultura familiar para viabilizar o desenvolvimento local e regional, por meio da diversificação da produção de alimentos e agregação de valor, contribuindo para a geração de renda e segurança alimentar e nutricional das famílias.

\section{Considerações finais}

Algumas estratégias são usadas pelos agricultores familiares para viabilizar melhorias na geração de renda. Dentre essas estratégias, agregar valor à produção é a principal, mas esse processo é feito predominantemente de forma artesanal e principalmente para autoconsumo. Assim, visando à comercialização da produção, esse processo ainda é incipiente em Mato Grosso do Sul.

A venda direta da produção é a modalidade de comercialização mais comum na agricultura familiar de Mato Grosso do Sul, porém a venda aos atravessadores ainda é elevada, representando quase 50\%, o que indica a necessidade de ações coletivas (entidades de produtores e/ou órgãos governamentais) para ampliar os canais de comercialização.

Há grande dificuldade no escoamento da produção dos agricultores familiares, pois a logística própria é muito fraca e também há predominância de estradas precárias, destacando-se como o principal gargalo na comercialização da produção oriunda da agricultura familiar em Mato Grosso do Sul.

Ações como o apoio para a construção de agroindústrias locais, a ampliação de canais de comercialização e a organização dos agricultores se destacam dentre as mais importantes soluções apontadas pelos agricultores para melhorar a comercialização dos produtos produzidos pela agricultura familiar nesse estado.

Tendo em vista a importância da agricultura familiar e suas características predominantes em Mato Grosso do Sul, evidencia-se a necessidade urgente da adoção de posturas proativas dos governos (federal, estadual e dos vários municípios) para apoiá-la em todas as etapas das cadeias produtivas, sob pena de os agricultores produzirem boa diversidade de produtos, porém não conseguirem acessar os 
mercados e não gerar renda satisfatória para atender às suas necessidades.

\section{Agradecimentos}

À Coordenação de Aperfeiçoamento de Pessoal de Nível Superior CAPES e à Fundação de Apoio ao Desenvolvimento do Ensino, Ciência e Tecnologia do Estado de Mato Grosso do Sul - FUNDECT, pela concessão de bolsas de mestrado e também aos agricultores que participaram da pesquisa.

\section{REFERÊNCIAS}

AGNE, C. L.; WAQUIL, P. D. Redes de proximidade: agricultores, instituições e consumidores na construção social dos mercados para os produtos das agroindústrias rurais familiares na Região Central do RS. REDES, v. 16, n. 1, p. 149-171, jan./abr. 2011.

AZEVEDO, F. F.; PESSÔA, V. L. S. O Programa Nacional de Fortalecimento da Agricultura Familiar no Brasil: uma análise sobre a distribuição regional e setorial dos recursos. Sociedade \& Natureza, v. 23, n. 3, p. 483-496, 2011.

BARCELOS, C. O. G.; REIS, C. V. S. Os níveis de renda dos assentados da agricultura familiar no Mato Grosso do Sul. Carta de Economia e Negócios, v. 1, n. 2-3, p. 11-13, 2015.

BEZERRA, G. J.; SCHLINDWEIN, M. M. Agricultura familiar tradicional no Brasil, com destaque para a região Centro-Oeste: perspectivas e dificuldades. In: CONGRESSO DA SOCIEDADE BRASILEIRA DE ECONOMIA, ADMINISTRAÇÃO E SOCIOLOGIA RURAL, 52. Anais... 2014, Goiânia - GO: SOBER, 2014. Goiânia - GO. Heterogeneidade e suas Implicações no Rural Brasileiro, 2014.

BRASIL. Senado Federal. Lei $n^{\circ} 11.326$, de 24 de julho de 2006. Institui a Política Nacional de Resíduos Sólidos; altera a Lei $n^{\circ}$ 9.605, de 12 de fevereiro de 1998; e dá outras providências. Disponível em: 
$<$ http://www.planalto.gov.br/ ccivil_03/_ato20042006/2006/lei/l1 1326.htm>. Acesso em: 3 mar. 2014.

COSTA, J. P.; RIMKUS, L. M.; REYDON, B. P. Agricultura familiar: Tentativas e estratégias para assegurar um mercado e uma renda. In: CONGRESSO DA SOCIEDADE BRASILEIRA DE ECONOMIA, ADMINISTRAÇÃO E SOCIOLOGIA RURAL, 46, Anais... 2008, Rio Branco: SOBER. Brasília: SOBER, 2008.

EUROPEAN SOCIETY FOR RURAL SOCIOLOGY. In: XXII Congress of the European Society for Rural Sociology. Anais... "Mobilities, Vulnerabilities and Sustainabilities: new questions and challenges for rural Europe". Netherlands, EU Wageningen, The Netherlands, EU, 20 - 24 August 2007.

DINIZ, J. D. A. S.; FIGUEIREDO, A. S. Integrated logistics in the supply of products originating from family farming organizations. In: RENKO, S. (Org.). Supply chain management. new perspectives. Rijeka, Croácia: Intech Open Access Publisher, 2011. p. 215-238.

FAMASUL - Federação da Agricultura e Pecuária de Mato Grosso do Sul. Safra 2014/2015 deverá ser superior a 200 milhões de toneladas. Disponível em: <http://famasul.com.br/noticias_interna/safra-20142015-devera-ser-superior-a-200-milhoes-de-toneladas/32005/>. Acesso em: 11 jan. 2015.

FULLER, Anthony M. From part-time farming to pluriactivity: a decade of change in rural Europe. Journal of Rural Studies, v. 6, n. 4, p. 361-373, 1990.

FURLANETO, H. L. R.; OLIVEIRA, J. T. A. de; ANDRADE, F. R. P. de. Renda, consumo de alimentos e insegurança alimentar de agricultores familiares de assentamentos rurais de Araras (estado de São Paulo). In: CONGRESSO DA SOCIEDADE BRASILEIRA DE ECONOMIA, ADMINISTRAÇÃO E SOCIOLOGIA RURAL, Anais... Vitória: Sober, 2012. 
GAZOLLA, M.; SCHNEIDER, S. Qual "fortalecimento" da agricultura familiar?: uma análise do Pronaf crédito de custeio e investimento no Rio Grande do Sul. Revista de Economia e Sociologia Rural, v. 51, n. 1, p. 45-68, 2013.

GUILHOTO, J. J. M.; AZZONI, C. R.; SILVEIRA, F. G.; ICHIHARA, S. M.; DINIZ, B. P. C.; MOREIRA, G. R. C. PIB da Agricultura Familiar. BrasilEstados. Brasília, DF: Editora NEAD, 2007. 172 p. (Estudos, n. 19).

HANASHIRO, M. M.; MATSUURA, F. C. A. U.; LIMA, I. A.; BERIAM, L. O. S.; MADDARENA, E. F.; MINITTI, A. F.; COMITRE, V.; PIMENTEL, M. A. A.; SOUZA, E. D. Transferência de tecnologias apropriadas para a agricultura familiar: uma experiência de ação integrada no estado de São Paulo. Cadernos de Ciência \& Tecnologia, v. 28, n. 1, p. 51-80, jan./abr. 2011.

IBGE - Instituto Brasileiro de Geografia e Estatística. Censo agropecuário 2006: Brasil, Grandes Regiões e Unidades da Federação. Disponível em: <http://www.ibge.gov.br/home/estatistica/economia/agropecuaria/cen soagro/brasil_2006/Brasil_censoagro2006.pdf >. Acesso em: 7 nov. 2015.

LOURENZANI, A. E. B. S.; LOURENZANI, W. L.; BATALHA, M. O. Barreiras e oportunidades na comercialização de plantas medicinais provenientes da agricultura familiar. Informações Econômicas, v. 34, n. 3, p. 15-25, 2004.

MAPA - Ministério da Agricultura, Pecuária e Abastecimento. Exportação. Disponível em: <http://www.agricultura.gov.br/vegetal>. Acesso em: 21 fev. 2015.

MARTINEZ, E. Á.; PEIL, R. M. N. Caracterização da comercialização e da diversidade da produção dos agricultores familiares associados à cooperativa sul ecológica. Current Agricultural Science and Technology, v. 16, n. 1-4, 2013. 
MATTEI, L. O papel e a importância da agricultura familiar no desenvolvimento rural brasileiro contemporâneo. Revista Econômica do Nordeste, v. 45, suplemento especial, p. 83-91, 2014.

MEDRADO, S. DOS S.; PAES-DE-SOUZA, M.; VASCONCELOS, J. de; JUSTEN, G. S.; ROSA, Q. da S. Participação da castanha-da-amazônia na composição da renda das famílias de reservas extrativistas do estado de Rondônia. In: CONGRESSO DA SOCIEDADE BRASILEIRA DE ECONOMIA, ADMINISTRAÇÃO E SOCIOLOGIA RURAL, Anais... Goiânia: Sober, 2014.

MIOR, L. C.; FERRARI, D. L.; MARCONDES, T.; REITER, J. M. W.; ARAUJO, L. A. Inovações organizacionais da agricultura familiar: as agroindústrias e cooperativas descentralizadas no Sul Catarinense. In: CONGRESSO DA SOCIEDADE BRASILEIRA DE ECONOMIA, ADMINISTRAÇÃO E SOCIOLOGIA RURAL, Anais... Goiânia: Sober, 2014.

MDA - Ministério do Desenvolvimento Agrário. Pesquisa do NEAD revela participação da agricultura familiar no PIB do Brasil, 2012. Disponível em: $\quad<$ http://www.mda.gov.br/sitemda/noticias/pesquisa-do-neadrevela-participa \%C3\%A7\%C3\%A3o-da-agricultura-familiar-no-pib-dobrasil>. Acesso em: 7 nov. 2015.

MONEGO, E. T.; ALEXANDRE, V. P. SOUSA, L. M.; MARTINS, K. A.; ROSA, J. Q. S.; SOUZA, P. L. C.; ASSIS, J. N. Agricultural production and potential and foods intended for schools in Goiás and Distrito Federal, located in the Midwest Region of Brazil. Revista de Nutrição, v. 26, n. 2, p. 233$241,2013$.

NASCIMENTO, J. S.; CONCEIÇÃO, V.; LUZ, B. M. O.; ALTEMIO, A. D. C.; PINEDO, R. A.; OLIVEIRA, E. R. Levantamento das Potencialidades da Pecuária Leiteira e Fruticultura no Assentamento Santa Olga em Nova Andradina estado do Mato Grosso do Sul. Cadernos de Agroecologia, v. 9, n. 4, 2014.

PADUA-GOMES, J. B.; PADOVAN, M. P. Agricultura orgânica de base familiar em Mato Grosso do Sul: um panorama sobre a produção, 
desafios e potencialidades do setor. Saarbrücken, Germany: Novas Edições Acadêmicas, 2014. 100 p.

RADWANSKI, E. M.; SAMPAIO, C. A. C.; SOBRAL, M. do C. M. Agregação de valor à agricultura familiar: uma alternativa para o desenvolvimento territorial sustentável. REDES, v. 19, n. 3, p. 74-96, 2014.

SANGALLI, A. R.; SCHLINDWEIN, M. M. A contribuição da agricultura familiar para o desenvolvimento rural de Mato Grosso do Sul - Brasil. REDES, v. 18, n. 3, p. 82-99, 2013.

SANTOS, A. M. dos; MITJA, D. Agricultura familiar e desenvolvimento local: os desafios para a sustentabilidade econômico-ecológica na comunidade de Palmares II, Parauapebas, PA. Interações, v. 13, n. 1, p. 39-48, 2012.

SCHNEIDER, S. Teoria social, agricultura familiar e pluriatividade. Revista Brasileira de Ciências Sociais, v. 18, n. 51, p. 99-121, 2003.

SCHNEIDER, S. Trends and matters in rural development studies in Brazil. In: CONGRESS OF THE EUROPEAN SOCIETY FOR RURAL SOCIOLOGY, 22, 2007, Wageningen, 2007.

SCHNEIDER, S.; CASSOL, A. Diversidade e heterogeneidade da agricultura familiar no Brasil e algumas implicações para políticas públicas. Cadernos de Ciência \& Tecnologia, v. 31, n. 2, p. 227-263, 2014.

SILVA, G. G.; CHEUNG, T. L.; VILPOUX, O. F.; SANCHES, F. T. Capital social e cooperação na agricultura familiar: uma análise comparativa entre os estados de Mato Grosso do Sul e Santa Catarina. Organizações Rurais \& Agroindustriais, v. 16, n. 2, 2014.

SANTOS, A. M.; MITJA, D. Family agriculture and local development: challenges to sustainable economic and ecological community of Palmares II Parauapebas city, Pará state in Brazil. Interações, v. 13, n. 1, p. 39-48, 2012. 
SOUZA-ESQUERDO, V. F. de; BERGAMASCO, S. M. P. P. Análise sobre o acesso aos programas de políticas públicas da agricultura familiar nos municípios do circuito das frutas (SP). Revista de Economia e Sociologia Rural, v. 52, suplemento 1, 2014.

VILCKAS, M.; NANTES, F. D. Agregação de valor: uma alternativa para a expansão do mercado de alimentos orgânicos. Organizações Rurais \& Agroindustriais, v. 9, n. 1, 2011.

WANDERLEY, M. N. B. Agricultura familiar e campesinato: rupturas e continuidade. Estudos Sociedade e Agricultura, v. 1, 2013.

WILKINSON, J. Mercados, redes e valores. Porto Alegre, RS: Ed. UFRGS, 2008.

Submetido em 15/06/2015

Aprovado em 06/01/2016

Jaqueline Silva Nascimento

Mestre em Agronegócios pela Universidade Federal da Grande Dourados. Estagiária na Embrapa Agropecuária Oeste.

E-mail: jaque24nascimento@hotmail.com

\section{Gleicy Jardi Bezerra}

Doutorado em andamento em Agronegócios na Universidade Federal do Rio Grande do Sul.

E-mail: gjardibezerra@gmail.com

Madalena Maria Schlindwein

Professora e pesquisadora da Universidade Federal da Grande Dourados-UFGD. E-mail: madalenaschlindwein@ufgd.edu.br

\section{Milton Parron Padovan}

Pesquisador da Embrapa Agropecuária Oeste e Professor Universidade Federal da Grande Dourados-UFGD.

E-mail: milton.padovan@embrapa.br 